\title{
A Review of the Possibility in Applying Game Theory to Libraries
}

Sureni Weerasinghe ${ }^{1}$

\begin{abstract}
This study aims to review literature on classical game theory applications in libraries and enable librarians to identify which games may be played in response to various decision-making situations especially in uncertain settings. Also this review paper provides approaches that are helpful for library cooperation. This study is mainly based on works of Hayes (2003), of various game theoretical concepts and applications of those in the library setting and explores the value of game theory concepts in helping libraries deal with management issues and library cooperation which is not widely practiced among libraries.
\end{abstract}

Keywords: Game theory, decision-making, library cooperation, mixed strategy, Shapely Value

\section{Introduction}

Game Theory which is a branch of applied mathematics captured the attention of social scientists soon after World War II, with the publication of von Neumann and Oskar Morgenstern's “Theory of Games and Economic behavior", in 1944 and a game was defined by them as "any interaction between agents that is governed by a set of rules specifying the possible moves for each participant and a set of outcomes for each possible combination of moves" (Heap \& Varoufakis, 1995). Game theory could be applied to any social interaction where people have an understanding of how the outcome for one person is influenced not only by his actions but also by the actions of others (Heap \& Varoufakis, 1995). Assuming that players are "instrumentally rational" and "act in their own best interests" game theory

\footnotetext{
${ }^{1}$ Assistant Librarian, University of Peradeniya, Sri Lanka, Email: sureniw1@yahoo.com
} 
discovers the optimal solutions for cooperative as well as conflicted situations (Kelly, 2003).

This research reviews the application of classical game theory in the library setting and provides possible approaches which are helpful for rational decision-making of the library management. Even though many research articles have been published on the application of game theory in various fields such as intelligent agents, economics and information technology a small amount were based on the application of game theory in libraries (Zhong \& Hegde, 2008). The strategies of game theory could support libraries deal with economic and management issues in uncertain circumstances (Zhong \& Hegde, 2008).

\section{Game Theory in Decision Making}

\section{Decision Problems}

Every person has to face decision-making in their day to day lives. In organizations decision- making is a daily process. Effective decisions are beneficial for the organization while unsuccessful ones create losses and in the decision making process, one option must be selected among possible alternatives. Decision-making is normally hard and complex. According to Gupta and Hira (2007), "The decision-maker is not only faced with a large number of interacting variables, which at times do not lend themselves to neat quantitative treatment, but also finds them too numerous and dynamic" and also the decision-maker has to consider the actions of the competitors over which there is no control .

In libraries important decisions should be made by librarians/assistant librarians. Decisions to be made in libraries vary from hiring decisions to those administrating day to day operations. Cooperative game theory concepts could be very useful when making decisions in library cooperation since "negotiation and cooperation among libraries is of special economic importance" mainly in situations such as shared cataloguing, shared acquisitions, shared storage, preservation and access (Hayes, 2003). Hayes (2003) asserts that, basically a library manager may face problems that are hard to understand, problems with unobvious objectives and unknown 
alternative solutions. He further explains that, by defining a suitable "utility function" the difficulties which will arise when representing the objectives could be settled.

\section{Utility Functions}

A "utility function" in game theory is a "quantitative representation of players' preference relations over the possible outcomes of the game" (Maschler et al., 2013). A higher value for utility indicates that the outcome is more preferred. The real value of the pay-offs (utilities) will be significantly different from player to player which could be seen by the example: a pay-off of one hundred Rupees to a poor person will be of a greater value to him than the same pay-off to a millionaire (Mendelson, 2004).

Using utility functions the payoffs of players in a game theory model could be represented according to Hayes (2003) as follows: Let $\mathrm{U}\left(\mathrm{x}_{1}\right)$ and $\mathrm{U}\left(\mathrm{x}_{2}\right)$ be the respective pay-offs for options $\mathrm{x}_{1}$ and $\mathrm{x}_{2}$ respectively, when $\mathrm{U}(\mathrm{x})$ is the Utility function and then for any two options $\mathrm{x}_{1}$ and $\mathrm{x}_{2}$, either $\mathrm{U}\left(\mathrm{x}_{1}\right)>\mathrm{U}\left(\mathrm{x}_{2}\right)$ $\Rightarrow$ option $\mathrm{x}_{1}$ is preferred to $\mathrm{x}_{2}, \mathrm{U}\left(\mathrm{x}_{1}\right)=\mathrm{U}\left(\mathrm{x}_{2}\right) \Rightarrow$ both the options are preferred equally, or $\mathrm{U}\left(\mathrm{x}_{2}\right)>\mathrm{U}\left(\mathrm{x}_{1}\right) \Rightarrow$ option $\mathrm{x}_{2}$ is preferred to $\mathrm{x}_{1}$. The utility function must be an order-preserving transformation since both $\mathrm{U}\left(\mathrm{x}_{1}\right)>\mathrm{U}\left(\mathrm{x}_{2}\right)$ and $\mathrm{U}\left(\mathrm{x}_{2}\right)>\mathrm{U}\left(\mathrm{x}_{1}\right)$ could not occur simultaneously (Hayes, 2003).

Let's consider the example demonstrated by Hayes (2003), with some modifications for illustration: Suppose as an assistant librarian the author has two goals in mind: to increase providing access to more E-journals through the library data base and to decrease the net cost in subscribing E-journals. The two objectives are in contrast with each other, since decreases in costs will result in decreases in access, but there may be solutions that would satisfy both objectives. The two goals could be compared by defining an appropriate utility function. The first objective deals with quantitative data while the second objective is qualitative and cannot be assessed numerically and hence the objective with a qualitative measure must be converted, into a quantitative measure. For example "increase in access" could be measured 
by the combination of "response time" and "frequency of access" which has a numerical value (Hayes, 2003).

\section{Game Theoretical Models}

After defining a suitable utility function a decision-problem could be represented by the utility values or pay-offs estimated for each of the alternative solutions of the problem. In real world problems library managers face uncertainties over which they have no direct control. Hayes (2003) states that, to represent those uncertain situations "potential contexts" can be included and when evaluating a set of alternative solutions to a problem, each solution is assessed for its utility across each context. The game theoretic model is a matrix with the rows being the options for alternative solutions, the columns are the contexts, and the elements of the matrix are the utilities or pay-offs. This matrix is also known as a "payoff matrix".

The rows and columns of a matrix that represents a normal competitive game consist of strategies of the player (decision-maker) and the opponent. The simplest type of game is a two-player zero-sum game in which the two players select their strategies simultaneously. For example, when the player uses strategy 1 and the opponent uses strategy 3 , player receives the payoff $\mathrm{U}_{13}$ from the opponent (refer table 1) and a positive number is a gain for the player (a loss for the opponent) and a negative number is a loss for him (a gain for the opponent).One player's gain would be the loss of the other, hence providing the "zero-sum feature" and the payoff received when the two players choose their strategies is known as the "value of the game" (Ventizel, 1961).

Table 1: A game theory model of a two-person game

\begin{tabular}{|l|l|l|l|l|}
\hline \multirow{2}{*}{$\begin{array}{l}\text { OPTIONS } \\
\text { player) }\end{array}$} & \multicolumn{4}{|c|}{ CONTEXTS (opponent) } \\
\cline { 2 - 5 } & 1 & \multicolumn{2}{|c|}{2} \\
\hline 1 & $U_{11}$ & $U_{I 2}$ & $U_{13}$ & $U_{14}$ \\
\hline 2 & $U_{21}$ & $U_{22}$ & $U_{23}$ & $U_{24}$ \\
\hline 3 & $U_{31}$ & $U_{32}$ & $U_{33}$ & $U_{34}$ \\
\hline
\end{tabular}


Based on the approach of Hayes (2003), let's consider a numerical example for illustration of the application of the "two-person zero sum game" into libraries, as follows: Suppose a library manager has to decide among 4 options across four uncertain situations for which he has no control. These uncertain situations are taken as the contexts. Suppose the assessments of utilities are as follows:

Table 2: Numerical example of a two-person game

\begin{tabular}{|l|l|l|l|l|}
\hline \multirow{2}{*}{$\begin{array}{l}\text { OPTIONS } \\
\text { (player) }\end{array}$} & \multicolumn{4}{|l|}{ CONTEXTS (opponent) } \\
\cline { 2 - 6 } & 1 & \multicolumn{2}{|c|}{2} & \multicolumn{2}{l|}{4} \\
\hline 1 & -5 & 3 & 1 & 8 \\
\hline 2 & 5 & 5 & 4 & 6 \\
\hline 3 & -4 & 6 & 0 & 5 \\
\hline
\end{tabular}

According to the utility values stated in table 2, the decision-maker may choose option 1 because he will gain 8 in context 4 (or when the opponent plays strategy 4).But he has to bear a loss of 5 (gain of -5) if the opponent selects context 1 . The best option could be selected by applying the "minimax principle" and it provides the solution of each player by either minimizing the maximum utility or by maximizing the minimum utility (Ventizel, 1961). According to the minimax principle, the solution can be calculated as follows:

$$
\begin{aligned}
\alpha & =\max \{\min (-5,3,1,8), \min (5,5,4,6), \min (-4,6,0,5)\} \\
& =\max (-5,4,-4) \\
& =4
\end{aligned}
$$

Therefore the decision-maker should choose option 2 in context 3.

Then he can assure a yield not less than $\alpha$ in any context, whatever strategy the opponent plays and the value $\alpha$ is called the "lower value" of the game. When the set of contexts are treated as the strategies of a competitor, similarly the competitor will try to maximize the minimum utility for him (Hayes, 2003) and since negative values would be gains for him across the set of options of player 1 , the maximum utility value should be determined 
and the solution will be the option for which the maximum utility is the smallest. It could be calculated as follows:

$$
\begin{aligned}
\beta & =\min \{\max (-5,5,-4), \max (3,5,6), \max (1,4,0), \max (8,6,5)\} \\
& =\min (5,6,4,8) \\
& =4
\end{aligned}
$$

Therefore the opponent should choose context 3 across option 2 .

Then he can assure a loss not more than $\beta$ in any context, whatever the player does and the value $\beta$ is called the "upper" value of the game.

In this example $\alpha=\beta$. That is, "the best strategies for the two competitors produce the same solution" (Hayes, 2003) which is option 2 and context 3. Such a game is a one with a "Saddle point" where the lower value of the game is the same as the upper value.

Suppose a library needs to provide better services to users compared to another library. Then the situation could be considered as a "two-person, zero- sum competitive game" between the two libraries. This concept of game theory can be used by each library respectively to determine the best strategy among several possible strategies. Also libraries face competition from other information providers such as bookstores, television and the internet (Zhong and Hegde, 2008) and each information provider should make decisions on what strategies to use to market their products and to attract more users. In such situations libraries can be considered as one player while all others as the opponent and apply game theory to determine strategies that are beneficial (Zhong and Hegde, 2008).

\section{Mixed Strategies in Game Theory}

In practical situations most games do not have a "saddle point" and in such games rather than applying the maximin strategy the player could gain more by selecting combined strategies that consist of several pure strategies chosen randomly but with definite frequencies (Ventizel, 1961). The concept of "mixed strategies" demonstrates this approach. Clearly every pure strategy is a particular case of a mixed strategy in which all strategies except one are chosen with zero frequencies, and the given one with a frequency of one 
(Ventizel, 1961).In order to determine the best mixed strategy a set of linear equalities and inequalities should be solved and this could be done by the use of methods in "linear programming" (Vajda, 1968). For illustration let's consider a game without a saddle-point.

Table 3: A game theory model with a saddle-point

\begin{tabular}{|c|c|c|c|c|}
\hline \multirow{2}{*}{$\begin{array}{l}\text { OPTIONS } \\
\text { (player1) }\end{array}$} & \multicolumn{4}{|c|}{ CONTEXTS (opponent or player2) } \\
\hline & 1 & & & $\alpha_{i}$ \\
\hline 1 & 1 & -1 & 3 & -1 \\
\hline 2 & 3 & 5 & -3 & -3 \\
\hline 3 & 6 & 2 & -2 & -2 \\
\hline$\beta_{j}$ & 6 & 5 & 3 & \\
\hline
\end{tabular}

(Source: Vajda, 1968).

Here, $\alpha=-1, \beta=3$

The inequalities for the decision maker are: $p_{1}+3 p_{2}+6 p_{3} \geq G,-1 p_{1}+5 p_{2}+2 p_{3} \geq G, 3 p_{1}-3 p_{2}-2 p_{3} \geq G$

Those for the opponent are:

$q_{1}-q_{2}+3 q_{3} \leq G, 3 q_{1}+5 q_{2}-3 q_{3} \leq G, 6 q_{1}+2 q_{2}-2 q_{3} \leq G$.

$G$ is the "value of the game" and $p_{i}$ and $q_{i}(i=1,2,3)$ denotes the relative frequency for each option.

The above problem could be solved by transforming it into a linear programming problem and solving by the methods of linear programming. Then the following values could be obtained: the value of the game is $G=1$ and the optimal strategies are $p_{1}=2 / 3, p_{2}=1 / 3, p_{3}=0$ for $A$, and, $q_{1}=0, q_{2}=1 / 2, q_{3}=1 / 2$ for $B$. When applying mixed strategies "each player wants the results, $G$ from the game to be the best possible for himself" (Hayes, 2003).

In the above example, if the opponent chooses option 1 then the result for the decision-maker (player), from the first inequality will be greater than $G$, while the results from other two inequalities are equal to $G$ which is beneficial for the decision-maker and hence $q_{1}$ is zero meaning that the 
opponent will not select option 1 under any circumstances. Similarly, if the decision-maker selects option 3 then the result for the opponent, from the third inequality will be less than $G$ while the results from other two inequalities are equal to $G$. This means that the player does not want to select option 3 under any circumstances, and hence $p_{3}$ is zero.

The above example could be analyzed in the point of view of libraries. Suppose two libraries (A and B) are considered to compete with each other in providing better services for the library users and the payoffs are given in the above matrix. Each library has 3 strategies to choose from. Then according to the results obtained library A (player) must choose strategy 1 with a probability of $2 / 3$ and strategy 2 with a probability of $1 / 3$ But he should not choose strategy 3 under any condition. That is because selecting strategy 3 would be beneficial for library B. In a similar manner library B's (opponent's) mixed strategy could be explained.

In another way, if the above matrix corresponds to the payoffs of a single decision-maker with 3 options across 3 contexts then the result can be analyzed as follows. The decision maker should select his $1^{\text {st }}$ option with a probability of $2 / 3$ and his $2^{\text {nd }}$ option with a probability of $1 / 3$. But he should not choose the $3^{\text {rd }}$ option under any circumstances. By using mixed strategies a librarian could select not only a single option but several options with definite probabilities.

\section{N-Player Games and the Shapley Value}

The games considered so far consist of only two players. When there are more than two players it is an N-player game (or multiple player game), where $\mathrm{N}$ is the number of players. In such games, to maximize their outcome players are expected to form coalitions for mutual benefits. A game becomes more complicated when cooperation among players is allowed. In cooperative games the inevitable assumption is that players could "form coalitions and make binding agreements" on the distribution of the payoffs of these coalitions and the game expresses what each possible coalition can receive through cooperation (Peters, 2008). 
In game theory, the Shapley value, introduced by Lloyd Shapley in 1953, is a "classical cooperative solution concept" (Winter, 2002). Shapley's idea was that players should obtain payoffs or shares proportional to their marginal contributions which give a 'fair' way for a coalition to divide its payoff among the players of the coalition (Hart, 1989).

Consider the following numerical examples for the illustration of the Shapely Value.

This example is equivalent to "sharing profits" between two business partners. Suppose two libraries (A \& B) have decided to provide access to different E-journals for their library users. Suppose, their individual benefits (profits) are assessed by the values $U(\mathrm{~A})=1$ and $U(\mathrm{~B})=2$ These utility values or payoffs should be determined by the decision-makers. Assessment of numerical values to "benefit" could be done using the "effectiveness" (Hayes, 2003) (measured by response time, accessing frequency etc) of accessing the E-journals by users. If the libraries cooperate with each other and share the benefits, suppose their payoff will be $U(\mathrm{~A}, \mathrm{~B})=4$. That is when they cooperate a higher value will be generated. Then how can one divide the total benefit (payoff- value 4) among the two libraries?

First consider the different ways (permutations) the coalition could be formed. There are only two members A and B. So, either A contributes first or then $\mathrm{B}$ will join in or the other way. That is, $(\mathrm{A}, \mathrm{B})$ or $(\mathrm{B}, \mathrm{A})$. When library $A$ joins first $A$ will contribute with a value of 1 and then when library $B$ joins in, $\mathrm{B}$ has to contribute the rest that is a value of 3 . Similarly when $\mathrm{B}$ contributes first with a value 2 then A will contribute the remaining 2 . Considering the average the resulting Shapley values are 1.5 for library A and 2.5 for library B. That is, library A will gain a payoff of 1.5 and library B will gain a payoff of 2.5 by cooperating and forming a coalition. By considering the above results both libraries could decide that cooperation is more beneficial than working individually. The above example demonstrates the application of Shapely value in the decision-making of library cooperation.

As another example, suppose three libraries (A, B, and C) are hoping to invest in microfilming books and it cost library A 70 , library B, 46 and library $\mathrm{C}, 60$ (all costs are in $10^{3}$ rupees). If the libraries cooperate to share 
the cost and form coalitions, let the amounts that should be paid by the libraries in each possible coalition are as follows: If only A and B cooperate their cost is 70 , for $A$ and $C$ it is 75 and for $B$ and $C$ it is 62. If all three libraries form a coalition together then the joint cost for this grand coalition will be 80 . All costs are in $10^{3}$ rupees. How much should each library pay if they form the grand coalition?

Table 4: Coalition of three libraries

\begin{tabular}{ll}
\hline $\begin{array}{l}\text { All possible } \\
\text { permutations }\end{array}$ & $\begin{array}{l}\text { Cost of each library A, B, C as if they were paying the } \\
\text { value of the coalition in turn }\end{array}$ \\
\hline (A, B, C) & $(70,0,10)$ \\
$(\mathrm{A}, \mathrm{C}, \mathrm{B})$ & $(70,5,5)$ \\
$(\mathrm{B}, \mathrm{A}, \mathrm{C})$ & $(24,46,10)$ \\
$(\mathrm{B}, \mathrm{C}, \mathrm{A})$ & $(18,46,16)$ \\
$(\mathrm{C}, \mathrm{A}, \mathrm{B})$ & $(15,5,60)$ \\
$(\mathrm{C}, \mathrm{B}, \mathrm{A})$ & $(18,2,60)$ \\
\hline \multicolumn{1}{c}{$\phi$} & 35.817 .426 .4 \\
& (values are rounded) \\
\hline
\end{tabular}

When the Shapley value of each library is calculated it shows that library A should invest 35.8 , library B should invest 17.4 and library C should invest 26.4 , in $10^{3}$ rupees. In this example sharing the cost among libraries than bearing it alone is certainly beneficial for all three libraries.

\section{Cooperative Decision -Making}

\section{Cooperative Games}

According to Brandenburger (2007), the theory of games can be divided into two branches known as the non-cooperative branch and the cooperative branch. Though "non-cooperative" and "cooperative" game theory are standard terms those can be quite misleading since they may suggest that cooperation is not allowed in the former and there is never a conflict in the latter, but these are in fact technical terms and do not assess the "degree of cooperation" among the players in the game theory model (Brandenburger ,2007). Cooperation can be also referred to as coalitions of two or more 
players acting together with a common goal in mind and since "rationality" and" intelligence" are two basic assumptions in game theory, any cooperation between players must consider the goal of maximizing their individual payoffs (Narahari, 2012).

(Drechsel, 2010) asserts that the foundation for cooperative game theory was developed by John Nash, through his work in Nash (1951), based on von Neumann and Morgenstern (1944)'s cooperative N-person game. Harsanyi and Selten (1988) continued to do research on Nash's findings and in 1994 Harsanyi, Selten and Nash jointly received the Nobel Prize in economics for their contributions to the theory of games (Drechsel, 2010).

Utility values which are means of representing the preferences of decisionmakers should be determined when developing any game theory model. "Linearity" is a necessary condition for the utility function to be quantitative (Hayes, 2006).

\section{Nash Bargaining Solution}

Bargaining problems represent situations where (i) "players have the possibility of concluding a mutually beneficial agreement" (ii) there is a conflict of interest about agreements and (iii) "no agreement may be imposed on any player without his approval" (Osborne and Rubinstein, 1990). According to Nash (1950), "A two-person bargaining situation involves two individuals who have the opportunity to collaborate for mutual benefit in more than one way". The "solution" of the bargaining problem is to find the "amount of satisfaction" each player could anticipate to obtain or in other words to determine how much it is worth for each player to involve in this bargaining process (Nash, 1950).In (Nash, 1950), a mathematical model is formed using numerical utility values to represent the preferences of each player joined in bargaining and each player would try to"maximize his gain in bargaining" (Osborne and Rubinstein, 1990).

The theory presented by Nash, in Nash (1953), involves situations where "two individuals whose interests are neither completely opposed nor completely coincident". Nash (1953) states that, in cooperative decision- 
making the two individuals should be able to discuss the situation and agree on a "rational joint plan of action". The issue in cooperation is to make a joint decision concerning the choice of the strategies that would maximize the joint utility (Hayes, 2006).

\section{Illustrative application of Nash bargaining solution in library cooperation}

Let's observe the problem considered by Nash (1950) which provided the basis of modern bargaining theory. Through this example the application of the concept Nash Bargaining solution, in library cooperation is illustrated.

Table 5: Table Illustrating the Nash Bargaining solution

\begin{tabular}{|l|l|l|}
\hline Choice & Cost to A & Value to B \\
\hline 1 & -2 & 4 \\
\hline 2 & -2 & 2 \\
\hline 3 & -2 & 1 \\
\hline 4 & -2 & 2 \\
\hline 5 & -4 & 1 \\
\hline Choice & Value to A & Cost to B \\
\hline 6 & 10 & -1 \\
\hline 7 & 4 & -1 \\
\hline 8 & 6 & -2 \\
\hline 9 & 2 & -2 \\
\hline
\end{tabular}

(Source: Nash, 1950)

The Nash solution to the bargaining problem could be analyzed as follows:

The players will obtain better results through cooperation, both individually and together than the results they would gain through non-cooperation. Nash (1950) has proved that the product of the utility gains is maximized when the combination of choices is $(1,2,3,4,6,7,8)$. Then the payoffs are 12 for $\mathrm{A}$ and 5 for $\mathrm{B}$, the criterion product is $(12-0) *(5-0)=60$ and the values of zero represent the payoff of the players if they do not cooperate. Hayes (2003), explores that, obviously choice 5 should not be included since there would be a net loss generated and he further explains that for the combination with choice 9 included, that is $(1,2,3,4,6,7,8,9)$, the payoffs are 14 for A, 3 for B and the total is 17 which is equal to the total of the optimum choice but clearly, B is paying A but not receiving a fair amount through cooperation. 
Then the criterion product is $(14-0)^{*}(3-0)=42$ and this value is less than 60 which is the optimum solution (Hayes, 2003).Using Hayes (2003)'s approach table 5 can be interpreted in the perspective of libraries.

Suppose two faculty libraries (A and B) of University of Peradeniya, Sri Lanka are considering an agreement on cooperative purchasing of E-books. Nine subject areas are taken into account and library A is acclaimed in the first five subject fields while library B in the last four. According to Hayes (2003)'s idea, if library A were responsible to one of the first five subject areas then there would be costs in purchasing E-books in that area as well as additional costs to bear, such as costs to provide access to those for users of library B and Library B would save the costs in purchasing in that field because Library B could depend on the responsible library A. Suppose the values in table 5 represents the assessments of costs and benefits of the two libraries. Then according to the "Nash bargaining solution" (Nash, 1950) the solution for this cooperative game is: library A would agree to purchase Ebooks in the subject fields 1,2,3,4 while library B in the fields 6,7 and 8 and other subject fields are not considered. Through cooperation both libraries could gain a higher value (benefit) than if they do not agree to cooperate.

Since the Nash bargaining solution could be generalized to the N-person game, when there are 3 or more libraries involved the Nash solution could be determined accordingly. Hayes (2001) has created a LPM-Library planning, a program in the form of an excel spreadsheet, which could be used to determine the best combination out of all possible choices.

Practically the above concept could be applied to cooperation within Faculty libraries of University of Peradeniya, Sri Lanka. They could cooperate in purchasing E-books. Several faculties offer the same subject under various course combinations. For example the subject "Management" is offered in Faculty of Arts, Post Graduate Institute of Agriculture under MBA and Faculty of Science as an optional course. Instead of several Faculty libraries purchasing E-books on "Management" one library could obtain those and provide the access to others. Likewise each library could agree on purchasing in selected subject fields. The best way to cooperate could be found 
according to the concept of "Nash Bargaining solution", by using appropriate utility values. Other areas of library cooperation are shared cataloguing, shared storage, shared preservation and access, cooperative automation and even sharing staff and expertise could be practiced.

\section{Conclusion}

This review paper presents the possibility of applying various game theory concepts, starting from the simplest game which is a two person, zero-sum competitive game up to more complex concepts such as Nash bargaining solution, into decision making of the library management and also in library cooperation. Cooperation is part of the library profession. The following observations and suggestions could be provided through this research which shows that game theory is a powerful tool to be used by librarians in rational decision-making especially when facing uncertain circumstances.

When the library manager has to make decisions facing uncertain situations the two-person zero sum game could be used with suitable utility values to decide the best strategy. Even when cooperating/competing with another library these methods will be a useful tool in making decisions. By the use of the concepts of "mixed strategy" a library manager could use several options with definite probabilities other than choosing one option for a decision problem.

The Shapley value can be used to determine the way to distribute the total gains or total costs among libraries, when they cooperate with each other. The concepts of cooperative game theory specifically the Nash bargaining solution demonstrates how to negotiate and bargain between libraries to obtain a higher gain by cooperation than working alone. For cooperative purchasing of E-books, a detailed application of Nash concept is illustrated according to Hayes (2003)'s study, using specific utility values to represent the decision problem. This approach will be useful for cooperation among faculty libraries of Sri Lankan University libraries.

Library cooperation is not widely practiced in Sri Lankan University libraries, other than in areas such as inter library loans. Also many Sri Lankan librarians are not aware about game theory concepts which are very 
valuable in rational decision making. This study hopes to create an interest in librarians, to explore game theory and apply those in their day to day decision-making as well as to give more weight on library cooperation.

\section{References}

Brandenburger, A. (2007). Cooperative Game Theory. Retrieved from http://www.uib.cat/depart/deeweb/pdi/hdeelbm0/arxius_decisions_an d_games/cooperative_game_theory-brandenburger.pdf

Drechsel, J. (2010). Cooperative Lot Sizing Games in Supply Chains. Springer: Heidelberg.

Gupta, P. K. \& Hira, D. S. (2007). Operations Research. S. Chand: New Delhi.

Hart. S. (1989). Potential value and Consistency. Econometrica, 57(3), 589614.

Hayes, R. M. (2001). Models for Library Management, Decision-making and Planning. Academic Press: San Diego, CA.

Hayes, R. M. (2003). Cooperative Game Theoretical Models for Decision making in the contexts of Library Cooperation. Library Trends, 51(3), 441-461.

Heap, S. P. H. \&Varoufakis, Y. (1995). Game Theory: A Critical Introduction. Routledge: London.

Kelly, A. (2003). Decision-making Using Game Theory: An Introduction to Managers. Cambridge University Press: Cambridge.

Maschler, M., Solan, E. \& Zamir, S. (2013). Game Theory. Cambridge University Press: Cambridge.

Mendelson, E. (2004). Introducing Game Theory and Its Applications. Chapman and Hall/CRC: Florida.

Narahari, Y. (2012). Game Theory Lecture Notes. Retrieved from http://lcm.csa.iisc.ernet.in/gametheory/ln/web-cp2-bargaining.pdf

Nash, J. (1950). The Bargaining Problem. Econometrica, 18(2), 155-162.

Nash, J. (1953). Two-person Cooperative Games, Econometrica, 21(1), 128140.

Osborne, M. J. \& Rubinstein, A. (1990). Bargaining and Markets. Academic Press: Sandiego.

Peters, H. (2008). Game Theory: A Multi-Level Approach. Springer: Berlin. 
Rausser, G. C., Swinnen, J. \& Zusman, P. (2011). Political Power and Economic Policy: Theory, Analysis and Empirical Applications. Cambridge University Press: Cambridge.

Vajda, S. (1968). An Introduction to Linear Programming and the Theory of Games, Methuen: London.

Ventizel, E. S. (1961). Lectures on Game Theory. Hindustani Publishing Corpn : Delhi, India.

Winter, E. (2002). The Shapley value. In Aumann, R.J. and Hart, S. (Eds.) The Handbook of Game Theory with Economic applications. Retrieved from http://www.ma.huji.ac.il/ mseyal/shapley4to95.pdf

Zhong, Y. \& Hegde, A. (2008). Applying Game Theory in Libraries:

Review and Preview, Library Philosophy and Practice (e journal). Retrieved from http://digitalcommons.unl.edu/cgi/viewcontent.cgi?article=1208\& context=libphilprac.

Note: The numerical examples presented for illustration are taken from text books (cited) or are made up examples and are used to make the illustrations as concrete as possible. 